\title{
Appreciation
}

\section{Tribute to Dr. D. N. Atukorala}

Journal of the Ceylon College of Physicians, 2015, 46, 59

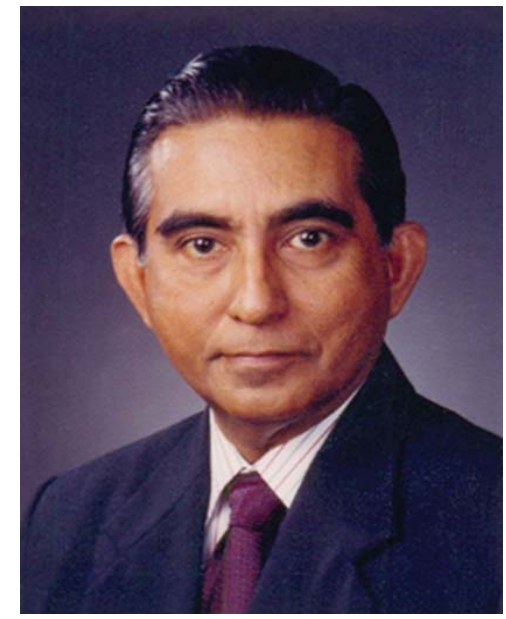

Donald Nandasiri Atukorala (who was affectionately called Atu by friends and colleagues) was born and blessed for educational achievement and professional recognition. He was an outstanding figure in the country, and a popular leader in the medical community. I was privileged to be his professional colleague, and we had a close association in dermatology for almost fifty years. We first met in 1967, when I was a Paediatric Dermatologist at the Lady Ridgeway Hospital for Children, and he the Senior House Officer in Dermatology, to Dr. V. T. Ratnaike, at the General Hospital, in Colombo.

His early and secondary education was at St. Thomas' College, Mt. Lavinia. Later he entered the Medical Faculty in Colombo, and qualified, MBBS, from the University of Ceylon, in 1964. He trained in dermatology and leprosy at the Institute of Dermatology, University of London, in 1972. Having obtained the Diploma in Dermatology, and membership of the Royal
College of Physicians of London in 1973, he took up the post of Additional Dermatologist at the Colombo General Hospital. He was Consultant Dermatologist at the Colombo South Teaching Hospital from 1977 to 1984, Consultant Dermatologist at Colombo North General Hospital (Ragama), later, and took up the post of Consultant Dermatologist at the National Hospital in Colombo from 1988, until retirement in 2000.

He was President of the Ceylon College of Physicians, and was awarded the FRCP (London), both in 1988, President of the Sri Lanka Association of Dermatology from 1996 to 1999, and of the Sri Lanka Medical Association in 1998, and, made an International Fellow of the American Academy of Dermatology in 1992.

Dr. Atukorala had more than 40 publications in medical journals, and authored chapters in 3 medical books. Atu was a Senior Lecturer at, and served on several boards of, the Postgraduate Institute of Medicine, - the Board of Management, the Board of Study in Medicine and in Dermatology. He was Chairman of the Dermatology Board since 1995.

He served as a volunteer in the Saukyadana Movement and was its Director General in 2004.

Atu passed away in February, 2015, and will be missed significantly in the professional organizations that he served with commitment.

\section{Dr. Lakshman Ranasinghe}

Founder President,

Sri Lanka College of Dermatology (1985). 